\title{
Educating Grade 6 students for higher-order thinking and its influence on creativity
}

\begin{tabular}{|c|c|}
\hline $\begin{array}{l}\text { Author: } \\
\text { Wajeeh Dahe } \\
\text { Amal Tabaja-K } \\
\text { Faaiz Gierdier }\end{array}$ & $\begin{array}{l}1,2 \text { (1) } \\
\text { idan }^{3}\end{array}$ \\
\hline $\begin{array}{l}\text { Affiliation: } \\
{ }^{1} \text { Mathematics } \\
\text { department, } \\
\text { Academic Col } \\
\text { Education, Ba }\end{array}$ & $\begin{array}{l}\text { education } \\
\text { l-Qasemi } \\
\text { ege of } \\
\text { qa, Israel }\end{array}$ \\
\hline $\begin{array}{l}{ }^{2} \text { Educational } \\
\text { An-Najah Nat } \\
\text { Nablus, Pales }\end{array}$ & $\begin{array}{l}\text { ciences Faculty, } \\
\text { onal University, } \\
\text { ine }\end{array}$ \\
\hline $\begin{array}{l}{ }^{3} \mathrm{Al}-\text { Qasemi Ac } \\
\text { of Education, }\end{array}$ & $\begin{array}{l}\text { ademic College } \\
\text { 3aqa, Israel }\end{array}$ \\
\hline $\begin{array}{l}{ }^{4} \text { Faculty of Ed } \\
\text { Stellenbosch } \\
\text { South Africa }\end{array}$ & $\begin{array}{l}\text { Ication, } \\
\text { Jniversity, }\end{array}$ \\
\hline $\begin{array}{l}\text { Correspondin } \\
\text { Wajeeh Dahe } \\
\text { wajeehdaher }\end{array}$ & $\begin{array}{l}\text { g author: } \\
\text { gemail.com }\end{array}$ \\
\hline $\begin{array}{l}\text { Dates: } \\
\text { Received: } 19 \\
\text { Accepted: } 31 \\
\text { Published: } 28\end{array}$ & $\begin{array}{l}\text { ugg. } 2016 \\
\text { May } 2017 \\
\text { Aug. } 2017\end{array}$ \\
\hline $\begin{array}{l}\text { How to cite th } \\
\text { Daher, W., Tab } \\
\text { Gierdien, F. (2 } \\
\text { Grade } 6 \text { stude } \\
\text { higher-order } \\
\text { influence on } \\
\text { Pythagoras, } 3 \\
\text { https://doi.or } \\
\text { pythagoras.v3 }\end{array}$ & $\begin{array}{l}\text { is article: } \\
\text { aja-Kidan, A., \& } \\
\text { 017). Educating } \\
\text { nts for } \\
\text { hinking and its } \\
\text { reativity. } \\
8(1), \text { a350. } \\
\text { (10.4102/ } \\
811.350\end{array}$ \\
\hline $\begin{array}{l}\text { Copyright: } \\
\text { (C) 2017. The A } \\
\text { Licensee: AOS } \\
\text { is licensed unc } \\
\text { Creative Comr } \\
\text { Attribution Lic }\end{array}$ & $\begin{array}{l}\text { uthors. } \\
\text { IS. This work } \\
\text { ler the } \\
\text { nons } \\
\text { ense. }\end{array}$ \\
\hline Read online: & \\
\hline 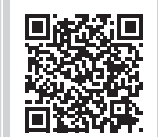 & $\begin{array}{l}\text { Scan this QR } \\
\text { code with your } \\
\text { smart phone or } \\
\text { mobile device } \\
\text { to read online. }\end{array}$ \\
\hline
\end{tabular}

Educating students for higher-order thinking provides them with tools that turn them into more critical thinkers. This supports them in overcoming life problems that they encounter, as well as becoming an integral part of the society. This students' education is attended to by educational organisations that emphasise the positive consequences of educating students for higher-order thinking, including creative thinking. One way to do that is through educational programmes that educate for higher-order thinking. One such programme is the Cognitive Research Trust (CoRT) thinking programme. The present research intended to examine the effect of the participation of Grade 6 students in a CoRT programme on their creative thinking. Fifty-three students participated in the research; 27 participated in a CoRT programme, while 26 did not participate in such programme. The ANCOVA test showed that the students who participated in the CoRT programme outperformed significantly, in creative thinking, the students who did not. Moreover, the students in the CoRT programme whose achievement scores were between 86 and 100 outperformed significantly the other achievement groups of students. Furthermore, students with reported high ability outperformed significantly the other ability groups of students. The results did not show statistically significant differences in students' creativity attributed to gender.

\section{Introduction}

Educating students towards higher-order thinking prepares them to be an integral part of the society, for this education strengthens their ability to confront life problems and find solutions to these problems (De Bono, 1992b; Papastephanou \& Angeli, 2007). This role of educating for thinking is behind educational organisations' call for teaching for higher-order thinking. This preparation can also be an impetus for reforming future education in mathematics (Kilpatrick, Swafford \& Findell, 2001; National Council of Teachers of Mathematics, 2000).

Higher-order thinking is associated with different thinking types. King, Goodson and Rohani (1998) say that higher-order thinking includes critical, logical, reflective, metacognitive, and creative thinking. In the present research, we are interested in students' creative thinking that is being made the focus of curriculum (Wilson, 2005), and being made an agenda for improving teaching and learning in the classroom (Burnard, 2006). This centeredness of creativity in current educational practices in the classroom has gone a long way since the call of Guilford (1950) for researchers' attention to it. This call resulted in great interest and attention of the educational researchers in students' creativity (Archambault, 1970). Torrance's (1966) tests of creative thinking could be regarded as a milestone in the area of creativity measurement. We use three components of creativity suggested by Torrance to examine Grade 6 students' mathematical creativity, as well as how this creativity is influenced by educating students in creative thinking and skills. Some of the participating students participated in a Cognitive Research Trust (CoRT) programme developed by De Bono (1992a) as an educating programme that aims to optimise and develop learners' thinking. We examine the differences in students' overall creativity and its components as a result of educating them through the CoRT programme.

\section{Research rationale and goals}

Piggott (2011) argues that creativity in the mathematics classroom is not only related to what pupils do but also to what teachers do, where the mathematical experiences that teachers offer their students can open up opportunities for them to be creative. Torrance (1972) describes several ways to teach students to think creatively. We adopted in the present research one of these ways, namely complex programmes involving packages of materials. As mentioned above, here we used the CoRT programme developed by De Bono (1992a) to teach Grade 6 students to think creatively. We examined how the participation in such programme affects students' creativity in 
problem solving, where this creativity is represented by its three components: fluency, flexibility and originality, as well as overall creativity. Our reported experiment follows different previous attempts (e.g. Craft, Cremin, Burnard \& Chappell, 2007), but ours is concerned with mathematical creativity. In our case, we engage upper primary students with a programme that aims to cultivate their thinking. In the mathematics classroom, studies suggest open-ended tasks (e.g. Mihajlović \& Dejić, 2015) or multiple solution tasks (e.g. Levav-Waynberg \& Leikin, 2012) for cultivating students' mathematical creativity. Here, we followed a different way of cultivating students' creativity, namely the CoRT programme. The different studies, including the present, point to different possible ways to develop students' mathematical creativity. This development would provide the student with powerful tools as a learner of mathematics in particular and of school disciplines in general.

\section{Research questions}

\section{Question 1}

How would participation in the CoRT programme influence Grade 6 students' mathematical creativity, including the three components of creativity (fluency, flexibility and originality) and including overall creativity?

\section{Question 2}

How would gender and mathematical achievement influence the creativity of Grade 6 students in general and those who participated in CoRT programme in particular?

\section{Theoretical framework and related literature}

Recognising and nurturing students' talents and thinking present an important challenge to educators (Marin \& Halpern, 2011). This suggests the need for tools for such nurturing. The CoRT programme is such tool, concerned with developing thinking, especially critical and creative thinking (Grissom, 2004).

De Bono (1992a, 1992b) developed cognitive tools for promoting thinking skills known as the CoRT with the first CoRT thinking lessons published in 1974. The CoRT programme (De Bono, 1992a) assumes that teachers can educate for thinking, thus educating for thinking can be part of the curriculum. The CoRT programme provides teachers with tools to teach thinking skills. It consists of over 60 lessons focusing on developing thinking skills. These 60 lessons range over six sections: Breadth, Organisation, Interaction, Creativity, Information and Feeling and Action. The CoRT section that was applied in the present study is CoRT (4) 'Creativity'. This section consists of 10 lessons: (1) Yes, No and Po ('Po', a device for showing that an idea is being used creatively without any judgment or immediate evaluation), (2) Stepping Stone (the use of ideas not for their own sake but because of other ideas they may lead to), (3) Random Input (the input of unrelated spurious ideas into a situation may change the situation),
(4) Concept Challenge (the testing of the 'uniqueness' of concepts may lead to other ways of doing things), (5) Dominant Idea (in most situations there is a dominant idea; in order to be creative one must find and escape from it), (6) Define the Problem (an effort to define a problem exactly may make it easier to solve), (7) Remove Faults (the assessment of faults and their removal from an idea), (8) Combination (by examining the attributes of seemingly unrelated items, new items may be created either by fusion or by combination), (9) Requirements (an awareness of requirements may influence the creation of ideas) and (10) Evaluation (does an idea fulfil the requirements; what are its advantages and disadvantages?). In the present research, we used the creativity section of the CoRT programme to encourage Grade 6 students' creative thinking in mathematics. See Appendix 1 for more detail on the activities given to the students in the frame of the programme.

Our interest in encouraging Grade 6 students' creative thinking in mathematics meets the call of educational institutions and researchers to encourage students to use high-order thinking skills, including creative thinking skills, because doing that prepares them to be 21st century citizens by possessing the appropriate skills (e.g. National Council of Teachers of Mathematics, 2000). This interest in nourishing students' creative thinking is due to its ability to support their problem solving through encouraging diverse solutions for a problem (Imai, 2000).

The prominence of creative thinking in education has been a response to the ongoing technological and scientific development (Leikin, 2013; Yazgan-Sağ \& Emre-Akdoğan, 2016). There is no single perspective or definition of creativity (Leikin \& Kloss, 2011; Mann, 2006; Sriraman, 2005). Mann (2006) claims that there are more than 100 definitions of creativity in the literature. Ervynck (1991) defines mathematical creativity as the ability to solve problems or develop structured thinking, as well as make connections in the mathematical content. He emphasises that creative activity is not related to algorithms, but to a novel concept, definition, argument or proof. In the present study, we draw on a definition of creativity as including three components: fluency, flexibility and originality (Guilford, 1950, 1975; Torrance, 1966). Fluency is associated with the number of correct answers that a student provides to a problem or correct questions the student poses with respect to a problem. Flexibility is associated with the number of answer or question types suggested for a problem, or with the number of problem-solving or problem-posing strategies that have been implemented. Originality is associated with the number of solutions offered or problems posed that very few or no other persons proposed (Torrance, 1966). This is also true for the present study. Specifically, when we evaluated the creativity components' scores, we followed Leikin (2009).

Recent studies have attempted to examine the effect of different variables on mathematical creativity. Leikin and Kloss (2011) studied the problem-solving performance of 8 th and 10th graders in terms of the correctness of their solutions and the three components of creativity (fluency, flexibility and originality). They found that Grade 10 students were 
significantly more successful and fluent when solving all the tasks, but nevertheless the differences between Grade 10's and Grade 8's flexibility, originality and creativity were task dependent. Moreover, their results showed that originality determines creativity stronger than fluency and flexibility.

Achievement and gender are two variables that have been studied for their effect on students' creativity, where different studies found different results concerning the effect of these two variables on students' creativity.

\section{Creativity and achievement}

Haylock (1997) points out that mathematical attainment can limit students in overcoming fixation and in working with divergent problems, although it does not determine their mathematical work. This statement agrees with research on the relation between creativity and achievement, which has been long researched (Baird, 1985; Torrance, 1962). We argue that this agreement means that mathematical attainment could influence one's creativity, but this influence could be mediated or moderated by other individual or social variables, such as motivation and teacher support. This conception of the relation between attainment and creativity can explain the literature that does not agree regarding the effect of achievement in a discipline on students' creativity in that discipline. While some studies have reported high correlations between academic achievement and creativity (e.g. Torrance, 1962), some have found low correlations between these two variables (e.g. Baird, 1985). Other studies have not found significant relations between achievement and creativity (e.g. Nori, 2002).

One of the studies that found significant differences in mathematical creativity and which is related to achievement is that of Mann (2005) who explored the relationship between mathematical creativity and mathematical achievement, attitude towards mathematics, self-perception of creative ability, gender and teacher perception of mathematical talent and creative ability. The research results indicated that $35 \%$ of the variance in mathematical creativity scores could be predicted by the studied variables. Mathematical achievement was the strongest predictor accounting for $23 \%$ of the variance. Students' attitudes towards mathematics, selfperception of their own creative ability and gender contributed the remaining $12 \%$ of variance.

\section{Creativity and gender}

Baer and Kaufman (2008) argue that no simple conclusions can be drawn from the empirical evidence on gender differences in creativity test scores (general creativity tests, not specific in a specific discipline). They enumerate studies that report women scoring higher than men in creativity (e.g. Misra, 2003), studies that report the opposite (e.g. Cox, 2003) and studies that report no difference (e.g. Kaufman, Baer \& Gentile, 2004).

In addition, some studies found significant and insignificant differences at the same time regarding the effect of gender on mathematical creativity. For example, Evans (1964) reported significant differences in Grade 7 and 8 students' scores of some creativity measures that could be attributed to gender, where girls outperformed boys. At the same time, Evans (1964) reported no significant differences between students' creativity scores in Grades 6 and 7.

In the present research, our main interest is with the interaction of the two variables, achievement and gender, with implementing the CoRT programme and how these interactions affected Grade 6 students' creativity. To evaluate students' creativity, we used multiple solution tasks.

\section{Multiple solution tasks for evaluating creativity}

A multiple solution task is a task that requires the student to solve a mathematical problem in different ways (Leikin, 2009). A multiple solution task has three solution spaces (Levav-Waynberg \& Leikin, 2012): expert solution space, individual solution space and collective solution space. An expert solution space includes the set of solutions to a problem known to an expert at a particular time. An individual solution space includes all the solutions produced by an individual. A collective solution space includes all the solutions produced by a group of students. These spaces are used for exploring students' mathematical creativity.

In the present study, we used multiple solution tasks to evaluate Grade 6 students' creativity in mathematics and to compare this creativity before and after participating in a CoRT programme.

\section{Cognitive Research Trust programme for encouraging higher-order thinking}

A number of studies have shown that the CoRT programme affects significantly higher-order thinking, including creative and critical thinking (e.g. Birdi, 2005). Al-Edwan (2011) explored the effectiveness of a training programme based on CoRT programme to develop Grade 7 students' critical thinking in a history course. The results showed statistical differences in the participating students' critical thinking in history as a result of the CoRT training programme. Moreover, Melhem and Isa (2013) explored the effect of using the CoRT programme on critical thinking skills among Grade 6 student with learning difficulties in mathematics. They found that the training programme positively and significantly affected the participants' critical thinking. In the present study, we intend to study the effect of the CoRT training programme on Grade 6 students' mathematical creativity.

Researchers have reported that the CoRT programme was effective for encouraging communication skills (e.g. Alshurman, 2017). Alshurman (2017) found that educating university students using the first section of the CoRT programme (Breadth) resulted in statistically significant differences between the pre and post communication skills scores in the experimental group in favour of the post measurement. Moreover, no statistically significant differences were found based on gender in the post scores. 
Concerning educating for creative thinking skills, researchers found that the CoRT programme helped in encouraging these skills (e.g. Al-Jallad, 2006). Al-Jallad (2006) reported that using the CoRT programme, as an educating programme, was effective for developing creative thinking skills among the female university students of the Arabic Language and the Islamic Studies. Little research has been done on the influence of the CoRT programme on mathematical creativity, which is the aim of the present research.

\section{Research hypotheses}

\section{Hypothesis 1}

Participation in the CoRT programme results in significant differences between the experimental group and the control group in Grade 6 students' mathematical creativity, including fluency, flexibility, originality and overall creativity.

\section{Hypothesis 2}

Participation in the CoRT programme results in significant differences between the scores of Grade 6 students' mathematical creativity, before and after the participation.

\section{Hypothesis 3}

Creativity scores of students who participate in the CoRT programme will not differ significantly according to the interaction of their gender and their participation in the programme.

\section{Hypothesis 4}

Creativity scores of students who participate in the CoRT programme will not differ significantly according to the interaction of their achievement and their participation in the programme.

In the first and second hypotheses, we followed other researchers who pointed to the positive influence of preparing students to use higher-order thinking, critical thinking or creative thinking on their actual use of this thinking. As mentioned above, researchers found that using the CoRT programme resulted in significant differences in critical thinking scores (Al-Edwan 2011; Melhem \& Isa, 2013).

In the third and fourth hypotheses, we followed researchers who found that gender and achievement did not result in significant differences in creativity scores when students participate in an education programme that encourages thinking creatively.

\section{Methodology \\ Research context and sample}

The present research intended to explore how a CoRT programme could affect Grade 6 students' mathematical creativity. The research was conducted in an Arab public elementary school in a small town (with population of approximately 30000 ) in the Haifa district in Israel. The school students come from middle socioeconomic backgrounds.
The research sample included two groups, with overall 53 Grade 6 students. The first group, the experimental group, included 27 students who participated in learning an Arithmetic unit based on the fourth section of the CoRT programme, that is, the creativity section, which included 10 lessons that encourage students' creativity. The second group, the control group, included 26 students who did not participate in the CoRT programme.

The present study is a quasi-experimental study. A quasiexperimental is an empirical study used to find the causal impact of an intervention on its target population without a random assignment. According to the definition of quasiexperimental research (see, for example, Kosslyn, 2017), this research shares similarities with the randomised controlled trial, but it specifically lacks the element of random assignment to experimental or control. Instead, the quasiexperimental design allows the researcher to control the assignment of subjects to the treatment condition, using some criterion other than random assignment (in our case scores in creativity and its components).

In addition to the above, the research design could be characterised as two-group design, with non-random selection and pre-test and post-test. This design is represented in Table 1.

The experimental group learnt the CoRT creativity section in groups of 3-5 students, in which student discussion was encouraged. The students were encouraged not to be afraid of having different answers, even if they were strange or controversial, and to discuss these answers with the rest of the group members. Moreover, the students had homework assignments to practise the new concepts and skills they learnt.

\section{Data collection tools}

The data were collected through pre- and post-tests on creativity. The two tests were similar but not identical. An example of a question in the pre-test is:

The sum of three natural numbers is 16 . The sum of two of them is equal to the third. What are the three natural numbers?

An example of a question in the post-test is:

The sum of four natural numbers is 20. The sum of two of them is equal to the sum of the other two. What are the four natural numbers?

\section{Data analysis tools}

To evaluate the components of creativity and overall creativity, we depended on the work of Leikin and Kloss (2011). We now describe our computations. Fluency (Fl) was evaluated by the number of solutions in the individual

TABLE 1: Research design.

\begin{tabular}{lccc}
\hline Group & Pre-test & Treatment & Post-test \\
\hline Experimental group & 0 & $X$ & 0 \\
Control group & 0 & & 0 \\
\hline
\end{tabular}

$\mathrm{X}$, indicates a treatment; $\mathrm{O}$, indicates an observation. 
solution space. Flexibility (Flx) was evaluated after building groups of solutions for the multiple solution tasks. Two solutions belonged to different groups if they employed solution strategies based on different representations, properties (theorems, definitions, or auxiliary constructions) or branches of mathematics. With respect to the corresponding solution spaces, we evaluated flexibility as follows: Flx $x_{1}=10$ for the first appropriate solution. For each following solution, $\mathrm{Flx}_{i}=10$ if it belonged to a group of solutions different from the solutions performed previously; $\mathrm{Flx}_{i}=1$ if the solution belonged to one of the previously used groups but had a clear minor distinction; $\mathrm{Flx}_{i}=0.1$ if the solution was almost identical to a previous solution. A student's total flexibility score on a problem was the sum of the student's flexibility on the solutions in the student's individual solution space. Originality (Or) was evaluated as follows: if $P$ is the percentage of students in the group that produces a particular solution, then $\mathrm{Or}_{\mathrm{i}}=10$, when $P<15 \%$ and for an insightbased or unconventional solution; $\mathrm{Or}_{i}=1$, when $15 \% \leq P<40 \%$ or for a model-based or partly unconventional solution; $\mathrm{Or}_{i}=0.1$ when $P \geq 40 \%$. A student's total originality score on a problem was the sum of the student's originality of the solutions in the student's individual solution space. The creativity $(\mathrm{Cr})$ of a particular solution is the product of the solution's originality and flexibility: $\mathrm{Cr}_{i}=\mathrm{Flx}_{i} \times \mathrm{Or}_{i}$. The total creativity score for a multiple solution task is the sum of the creativity scores for each solution in the individual solution space of a problem:

$\mathrm{Cr}=\sum_{i=1}^{n} \mathrm{Flx}_{i} \times \mathrm{Or}_{i}$

The scores of the components of creativity and overall creativity were coded in SPSS 21 to test the research hypotheses. The following computations were performed: means and standard deviations of the different creativity components and the overall creativity, one-way analysis of co-variance (ANCOVA) to verify the effect of the CoRT programme on students' creativity, analysis of variance (ANOVA) to verify the effect of the reported ability and the overall achievement on students' creativity and Eta squared $\left(\eta^{2}\right)$ as estimate of effect sized of the variables.

As for the verification of the first hypothesis, we ran ANCOVA and post-hoc tests to test whether there are significant differences between the creativity scores in the two research groups after the experiment, and ran paired $t$-test to test whether there were significant differences between the creativity scores in the CoRT group before and after implementing the CoRT programme.

As to the distribution of the participants regarding the independent variables, Table 2 describes the number and percentage of participants in terms of gender, reported ability and overall achievement.

The students in the two groups did not have significant differences in the components of creativity in the pre-test of creativity that the two groups took, as can be seen in Table 3 .

\section{Ethical consideration}

Before collecting the data, the second researcher received the permission of the Ministry of Education and the school headmaster. She also sought the permission of the participating students' parents.

\section{Findings}

\section{The effect of participation in Cognitive Research Trust programme on Grade 6 students' mathematical creativity}

To verify Hypothesis 1, we examined the effect of participation in CoRT programme on Grade 6 students' mathematical creativity using two methods: running ANCOVA and posthoc tests to test whether there are significant differences between the creativity scores in the two research groups. In addition, to verify Hypothesis 2, we ran paired $t$-test to test whether there are significant differences between the creativity scores in the CoRT group before and after the implementing the CoRT programme.

\section{Differences between the scores of the two research groups' creativity}

Table 4 shows the means and standard deviations of the scores of creativity and its components in the two research groups after the experiment.

We see from Table 4 that the scores of the experimental group are higher than those of the control group in creativity and its

TABLE 2: Number and percentage of participants in terms of gender, reported ability in mathematics and overall achievement.

\begin{tabular}{llcc}
\hline Variable & Category & \multicolumn{2}{c}{ Number (\%) } \\
\cline { 3 - 4 } & & $13(48.2)$ & $15(57.7)$ \\
\hline Gender & Male & $14(51.8)$ & $11(42.3)$ \\
& Female & $0(0.0)$ & $1(3.9)$ \\
Reported ability in mathematics & Weak & $12(44.4)$ & $7(26.9)$ \\
& Medium & $15(55.6)$ & $18(69.2)$ \\
& Strong & $5(18.5)$ & $2(7.7)$ \\
Overall achievement & 55 and less & $5(18.5)$ & $1(3.9)$ \\
& $56-75$ & $1(3.7)$ & $4(15.4)$ \\
& $76-85$ & $16(59.3)$ & $19(73.1)$ \\
\hline
\end{tabular}

TABLE 3: Means, standard deviations and $t$-test for creativity scores before the Cognitive Research Trust program ( $N=27$ for the experimental group and $N=26$ for the control group).

\begin{tabular}{lccrc}
\hline Group & Experimental $\boldsymbol{M}(\boldsymbol{S D})$ & Control $\boldsymbol{M}(\boldsymbol{S D})$ & $\boldsymbol{t}$ & $\boldsymbol{p}$ \\
\hline Fluency & $0.821(0.35)$ & $0.827(0.21)$ & -0.075 & 0.941 \\
Flexibility & $8.210(3.49)$ & $8.160(1.81)$ & 0.074 & 0.942 \\
Originality & $1.060(1.55)$ & $1.460(2.18)$ & -0.761 & 0.451 \\
Creativity & $19.270(42.83)$ & $21.520(46.65)$ & -0.183 & 0.856 \\
\hline
\end{tabular}

TABLE 4: Means and standard deviations for creativity scores after the Cognitive Research Trust programme ( $N=27$ for the experimental group and $N=26$ for the control group).

\begin{tabular}{lcc}
\hline Group & Experimental $\boldsymbol{M}(\boldsymbol{S D})$ & Control $\boldsymbol{M}(\boldsymbol{S D})$ \\
\hline Fluency & $1.36(0.75)$ & $0.90(0.20)$ \\
Flexibility & $13.25(6.86)$ & $8.86(1.71)$ \\
Originality & $4.99(5.84)$ & $1.36(2.37)$ \\
Creativity & $136.08(181.93)$ & $21.20(50.90)$ \\
\hline
\end{tabular}


components. To examine the significance of the differences in the means of creativity and its components of the two research groups, we ran ANCOVA. According to Montgomery (2013), running ANCOVA should be done after ensuring normality and equality of variance of the residuals of scores of the groups participating in the research. Testing for normality of the residuals of creativity scores in the two research groups, using the Shapiro-Wilk test (Shapiro \& Wilk, 1965), we found that the residuals of the creativity scores, including the components' scores, were distributed normally. We also ran Levene's test (e.g. Carroll \& Schneider, 1985) to examine the equality of variances of the residuals of creativity scores in the two research groups, which gave equality of variances of the residuals. We ran ANCOVA to examine whether there was significant difference between the creativity scores of the two research groups that could be related to the intervention, that is, participating in the CoRT programme. Though ANCOVA takes into consideration the creativity scores before the experiment, we ran independent $t$-tests to examine the difference in creativity scores of the two groups before the experiment. The results showed, as described above, that the means of the creativity scores of the two research groups before the experiment were not statistically significant at the 0.05 level.

The results of the ANCOVA test showed significant differences in creativity scores after the experiment between the CoRT programme group and the control group, with $F(1,50)=16.46, p=0.000$ for fluency; $F(1,50)=18.177$, $p=0.000$ for flexibility; $F(1,50)=17.13, p=0.000$ for originality; $F(1,50)=13.95, p=0.000$ for creativity. A look at R-squared $\left(r^{2}\right)$ showed that $r^{2}=0.520$ for fluency, $r^{2}=0.561$ for flexibility, $r^{2}=0.441$ for originality and $r^{2}=0.402$ for creativity.

The previous results show that the group of students who participated in the CoRT programme scored significantly higher in mathematical creativity and its components than the group of students who did not participate in the programme. These results indicate the acceptance of Hypothesis 1. At the same time, they imply that the CoRT programme accounted for $40 \%$ of the total variance in creativity as a consequence of the CoRT programme. This percentage is the $r^{2}$ value above for creativity and it indicates the contribution of the CoRT programme to the variance in creativity scores between the experimental and control group. This accounting for the variance is more in the components of creativity, where the $r^{2}$ values ranged between 0.441 and 0.561 .

\section{Differences in the creativity scores of the Cognitive Research Trust group before and after the experiment}

To verify Hypothesis 2, a paired-samples $t$-test was conducted to compare the creativity scores of the CoRT group before and after the experiment. The results showed that the creativity scores in the post-exam were significantly higher than those in the pre-exam: $t(52)=4.677, p=0.000, d=0.783$ for fluency; $t(52)=4.955, p=0.000, d=0.793$ for flexibility; $t(52)=3.396, p=0.001, d=0.585$ for originality; $t(52)=3.304$, $p=0.002, d=0.612$ for creativity. The effect sizes indicated that the difference between the creativity scores after and before the CoRT programme were medium to large (Dunst, Hamby \& Trivette, 2004). These results indicate the acceptance of Hypothesis 2.

\section{Effect of gender on the creativity of Grade 6 students who participated in the research in general and in Cognitive Research Trust programme in particular}

The results of the independent sample $t$-test showed no significant differences before the CoRT programme in creativity scores of Grade 6 students that could be attributed to gender. Moreover, to verify Hypothesis 3, we ran ANOVA test to examine the effect of gender on the creativity of students who participated in the CoRT programme (the effect of the interaction between the programme and gender). The results gave: $F(1,49)=3.162, p=0.061$ for fluency; $F(1,49)=2.332, p=0.133$ for flexibility; $F(1,49)=1.197$, $p=0.279$ for originality; $F(1,49)=0.962, p=0.332$ for creativity. All the significance values of $F$ s indicate that the interaction of gender with the intervention did not yield significant differences in the creativity of Grade 6 students who participated in the CoRT programme. These results indicate the acceptance of Hypothesis 3.

\section{Effect of mathematical achievement on the creativity of Grade 6 students who participated in Cognitive Research Trust programme}

The results of ANOVA test on creativity and its components' scores before the CoRT programme showed significant differences in fluency scores of Grade 6 students before the CoRT programme that could be attributed to achievement, $F(3,49)=7.869, p=0.000$. ANOVA also showed significant differences in flexibility scores before the experiment and that could be attributed to achievement, $F(3,49)=8.011$, $p=0.000$. Moreover, ANOVA showed no significant differences in originality or overall creativity scores that could be attributed to achievement. A look at $r^{2}$ showed that $r^{2}=0.325$ for fluency and $r^{2}=0.329$ for flexibility. At the same time, the post-hoc analysis, using Bonferroni's post-hoc test (e.g. Garcia \& Herrera, 2008), showed that fluency scores before the experiment in the 86-100 achievement group $(M=0.97, S D=0.23)$ was significantly higher than in the 0-55 achievement group $(M=0.64, S D=0.33)$ and significantly higher than in the 56-70 achievement group $(M=0.62$, $S D=0.26$ ). Furthermore, the post-hoc analysis, using Bonferroni's post-hoc test, showed that flexibility scores before the experiment in the 86-100 achievement group $(M=9.60, S D=2.07)$ was significantly higher than in the 0-55 achievement group $(M=6.43, S D=3.25)$ and significantly higher than in the 56-70 achievement group $(M=6.15$, $S D=2.58)$.

In addition, to verify Hypothesis 4, we ran the ANCOVA test to examine the effect of the interaction between the CoRT programme and mathematical achievement (the effect of 
mathematical achievement on the creativity of students who participated in the CoRT programme). The results gave: $F(3,45)=2.598, p=0.064$ for fluency; $F(3,45)=2.986, p=0.041$ for flexibility; $F(3,45)=1.418, p=0.250$ for originality; $F(3,45)=1.831, p=0.155$ for creativity. The significance values of Fs indicate that the interaction of achievement with the programme yielded significant differences only in flexibility scores of Grade 6 students who participated in the CoRT programme. These results indicate partial acceptance of Hypothesis 4.

Post-hoc analysis was conducted using Bonferroni's post-hoc test. The post-hoc analysis showed significant differences in students' fluency scores, as a result of the interaction between the programme and achievement. The fluency of students in the 56-70 achievement group $(M=0.70, S D=0.30)$ was significantly lower than in the 86-100 achievement group ( $M=1.74, S D=0.73)$. At the same time, the post-hoc analysis showed significant differences in students' flexibility scores, as a result of the interaction between the programme and achievement. The flexibility of students in the 86-100 achievement group $(M=16.84, S D=6.48)$ was significantly higher than in the 0-55 achievement group $(M=8.67$, $S D=3.21)$ and significantly higher than in the 56-70 achievement group $(M=7.00, S D=2.98)$.

The post-hoc analysis also showed significant differences in students' originality and overall creativity scores, as a result of the interaction between the programme and achievement. The originality of students in the 86-100 achievement group $(M=7.75, S D=6.16)$ was significantly higher than in the $56-70$ achievement group $(M=0.07, S D=0.03)$. Moreover, the creativity of students in the 86-100 achievement group $(M=215.98, S D=198.91)$ was significantly higher than in the 56-70 achievement group $(M=0.70, S D=0.30)$.

\section{Discussion}

The research results showed that the group of students who participated in the CoRT programme scored significantly higher in mathematical creativity and its components than the group of students who did not participate in the programme. At the same time, the research results showed that the scores of creativity and its components in the experimental group increased significantly as a result of the CoRT programme, that is, after the students were educated for creativity. Both results are due to the variety of creativity tasks in the CoRT creativity unit. This variety characterised the CoRT creativity unit through the 10 lessons that differ in the meanings they associate with creative thinking (for example, the sixth lesson educates for defining the problem in order to facilitate solving it in various ways, while the fifth lesson educates for finding the dominant idea in the problem in order to escape this idea and thus be creative). This variety of the lessons of the programme supported the students in arriving at a systematic approach to creative thinking, and thus in internalising the meanings of mathematical creativity represented in fluency, flexibility and originality. This internalisation is a result of the multiple representations of creativity presented in the 10 lessons. Furthermore, this internalisation made the students perform better in creativity and its components. Moreover, the mathematical questions included in the CoRT creativity unit encouraged multiple solutions of a problem (see Appendix 2), which supported students' internalisation of the meanings associated with creativity.

In addition to the explanation above, students' discussions in the group (see Appendix 3) motivated their thinking (Williams \& Williams, 2011) and, as a result, encouraged their creativity in solving mathematical problems. This process also contributed to the participating students' internalisation of the meanings of creativity, and thus motivated and increased the expressions of creativity and its components. Furthermore, the homework assignments helped the students in the experimental group practise the creativity skills associated with the three components of creativity, which motivated their thinking creatively.

The research results agree with previous studies which showed that CoRT creativity programme positively affected students' performance in creativity (e.g. Al-Edwan, 2011; Park \& Kwon, 2006). The research results also agree with Leiken (2009) who found that an educating programme that emphasised multiple solutions of a mathematical problem increased students' creativity.

Researchers do not agree on the effect of gender on creativity (Baer \& Kaufman, 2008). The results of the present study agree with studies that found no significant differences in Grade 6 students' creativity that could be related to gender (e.g. Kaufman et al., 2004). Furthermore, the present study showed no significant differences in creativity scores that are related to the interaction of education based on the CoRT programme and gender. Thus, the CoRT programme affected male and female students in the same way. This is also the case of the results reported by Alshurman (2017) who found that educating university students based on the CoRT programme showed no statistically significant differences in the post scores that could be related to gender.

The research results showed significant differences in fluency and flexibility scores of Grade 6 students before the CoRT programme that could be attributed to achievement, but they showed no significant differences in originality or overall creativity scores that could attributed to achievement. Researchers do not agree about the effect of achievement on students' creativity (Mann, 2005; Nori, 2002). Here too, the results were not unified. Achievement affects fluency and flexibility more than originality and overall creativity. We argue that fluency and flexibility are related to the students' formal learning of mathematics, which is not the case with originality, which is related to the production of novel ideas (Leikin \& Kloss, 2011), apparently not taken care of in a satisfactory manner in the students' formal learning of mathematics. In addition to the previous results, the post-hoc analysis showed that fluency and flexibility scores before the experiment in the 86-100 achievement group were 
significantly higher than in the $0-55$ and the 56-70 achievement groups. These results indicate that achievement needs to be very high in order to produce significantly higher scores in fluency and flexibility.

Examining the interaction of achievement with the CoRT programme, the post-hoc analysis showed that, in the experimental group, the 86-100 achievement group significantly outperformed the $0-55$ achievement group also in originality and overall creativity. These results show that the CoRT programme benefited the group with the highest achievement more than the one with the lowest achievement, but this was not the case with the other achievement groups. These results could be due to the more sophisticated learning means and learning strategies that the high achieving students have because of their richer learning history. Here, we assume that high achieving students could afford richer learning strategies and problem-solving skills than others (Stepanek, 1999). This explanation of the more sophisticated means and learning strategies agrees with Castejón, Gilar, Veas and Miñano (2016) who found that, in relation to learning strategies, underachieving students reported a lower use of strategies than the average and overachieving groups. This happened because, when learning, underachieving students processed less information and recovered it with more difficulty; in addition to that, they also transferred and applied less of what they learnt. Furthermore, Castejón et al. (2016) found that when underachieving students plan, they evaluate and control the learning pace and advancement to a lesser extent, which means that they apply less metacognitive strategies in learning. This application of less metacognitive strategies resulted in significantly lower scores of creativity (GutierrezBraojos, Salmeron-Vilchez, Martin-Romera \& Pérez, 2013).

\section{Conclusions}

Leikin (2013) points to the need for mathematics teachers to provide students with appropriate opportunities for developing their creative thinking. This is in line with the assumption that creativity is a public domain, so we should attend to developing it through special programmes (Joussemet \& Koestner, 1999). We examined, in the present research, the effect of a CoRT programme that targeted creativity in a direct way on developing Grade 6 students' mathematical creativity. The research results implied that the programme affected students' creativity positively, including fluency, flexibility, originality and overall creativity. The question whether educating programmes like the CoRT programme improve students' creativity was raised by Leikin (2009) who reviewed studies that found that it is possible to educate for fluency and flexibility but not for originality. In the present research, we found that educating for creativity can improve originality too. This could be due to the nature of the educating programme that targeted creativity in a direct way, so it resulted in improving not only students' fluency and flexibility, but originality too. More research is needed to verify the issue of the effect of educating programmes on mathematical creativity, especially mathematical originality.
One of the main questions that need special attention and further research is: what are the achievement levels of students who could be educated for creativity in general and specifically in originality?

\section{Acknowledgements Competing interests}

The authors declare that they have no financial or personal relationships that may have inappropriately influenced them in writing this article.

\section{Authors' contributions}

W.D. contributed mainly to the writing but was also engaged in the project design. A.T.-K. contributed mainly to the project design but was also engaged in the writing. F.G. contributed mainly to the writing process.

\section{References}

Al-Edwan, Z.S.M. (2011). The effectiveness of a training program based on cognitive research trust strategies to develop seventh grade students' critical thinking in history course. Journal of Social Sciences, 7(3), 436-442. https://doi.org/10.3844/ jssp.2011.436.442

Al-Jallad, M. (2006). The effectiveness of using the CoRT program on developing the creative thinking skills among the female students of the Arabic language and the Islamic studies at Ajman university network of science and technology. Journal of Umm Al-Qura University of Educational, Social and Humanitarian Sciences, 18(2), 147-180.

Alshurman, W.M. (2017). The effects of the first part of the CoRT program for teaching thinking (BREADTH) on the development of communication skills among a sample of students from Al al-Bayt University in Jordan. Educational Research and Reviews, 12(2), 73-82. https://doi.org/10.5897/ERR2016.3069

Archambault, F.X. (1970). A computerized approach to scoring verbal responses to the Torrance tests of creative thinking. Available from https://ia601304.us.archive. org/3/items/ERIC_ED038673/ERIC_ED038673.pdf

Baer, J., \& Kaufman, J.C. (2008). Gender differences in creativity. The Journal of Creative Behavior, 42(2), 75-105. https://doi.org/10.1002/j.2162-6057.2008. tb01289.x

Baird, L.L. (1985). Do grades and tests predict adult accomplishment? Research in Higher Education, 23(1), 3-85. https://doi.org/10.1007/BF00974070

Birdi, K.S. (2005). No idea? Evaluating the effectiveness of creativity training. Journal of European Industrial Training, 29(2/3), 102-111. https://doi.org/10.1108/ 03090590510585073

Burnard, P. (2006). Reflecting on the creativity agenda in education. Cambridge JournalofEducation,36(3),313-318.https://doi.org/10.1080/03057640600865801

Carroll, R.J., \& Schneider, H. (1985). A note on Levene's tests for equality of variances. Statistics and Probability Letters, 3(4), 191-194. https://doi.org/10.1016/0167 7152(85)90016-1

Castejón, J.L., Gilar, R., Veas, A., \& Miñano, P. (2016). Differences in learning strategies, goal orientations, and self-concept between overachieving, normal-achieving, and underachieving secondary students. Frontiers in Psychology, 7, Article 1438 https://doi.org/10.3389/fpsyg.2016.01438

Cox, B.F. (2003). The relationship between creativity and self-directed learning among adult community college students. Unpublished doctoral dissertation. University of Tennessee, Knoxville, Tennessee, Unites States. Available from http://trace. tennessee.edu/utk_graddiss/2531/

Craft, A., Cremin, T., Burnard, P., \& Chappell, K. (2007). Developing creative learning through possibility thinking with children aged 3-7. In A. Craft, T. Cremin, \& P. Burnard (Eds.), Creative learning 3-11 and how we document it (pp. 65-74). London: Trentham. Available from http://oro.open.ac.uk/12952/2/6F6D71D8.pdf

De Bono, E. (1992a). CoRT thinking. Des Moines, IA: McQuaig Group.

De Bono, E. (1992b). Teach your child how to think. London: Penguin Group.

Dunst, C.J., Hamby, D.W., \& Trivette, C.M. (2004). Guidelines for calculating effect sizes for practice-based research syntheses. CenterScope, 3(1), 1-10.

Ervynck, G. (1991). Mathematical creativity. In D. Tall (Ed.), Advanced mathematical thinking (pp. 42-53). Dordrecht: Kluwer.

Evans, E.W. (1964). Measuring the ability of students to respond in creative mathematical situations at the late elementary and early junior high school level. Dissertation Abstracts, 25(12), 7107. (UMI No. AAT 6505302).

Garcia, S., \& Herrera, F. (2008). An extension on 'statistical comparisons of classifiers over multiple data sets' for all pairwise comparisons. Journal of Machine Learning Research, 9(12), 2677-2694. Available from http://www.jmlr.org/papers/ volume9/garcia08a/garcia08a.pdf 
Grissom, T. (2004). Creative and critical thinking skills in practice. Available from http://www.ux1.eiu.edu/ csgtg/cimt862/grissom_paper1.pdf

Guilford, J.P. (1950). Creativity. American Psychologist, 5(9), 444-454. https://doi. org/10.1037/h0063487

Guilford, J.P. (1975). Factors and factors of personality. Psychological Bulletin, 83(5), 802-814. https://doi.org/10.1037/h0077101

Gutierrez-Braojos, C., Salmeron-Vilchez, P., Martin-Romera, A., \& Pérez, H.S. (2013). Direct and indirect effects between thinking styles, metacognitive strategies and creativity in college students. Annals of Psychology, 29(1), 159-170.

Haylock, D. (1997). Recognizing mathematical creativity in school children. ZDM: The International Journal on Mathematics Education, 29(3), 68-74. https://doi. org/10.1007/s11858-997-0002-y

Imai, T. (2000). The influence of overcoming fixation in mathematics towards divergent thinking in open-ended mathematics problems on Japanese junior high school students. International Journal of Mathematical Education in Science and students. International Journal of Mathematical Education in Scien
Technology, 31, 187-193. https://doi.org/10.1080/002073900287246

Joussemet, M., \& Koestner, R. (1999). Effect of expected rewards on children's creativity. Creativity Research Journal, 12(4), 231-239. https://doi.org/10.1207/ s15326934crj1204_1

Kaufman, J.C., Baer, J., \& Gentile, C.A., (2004). Differences in gender and ethnicity as measured by ratings of three writing tasks. Journal of Creative Behavior 39, 56-69. https://doi.org/10.1002/j.2162-6057.2004.tb01231.x

Kilpatrick, J., Swafford, J., \& Findell, B. (Eds.). (2001). Adding it up: Helping children learn mathematics. Washington, DC: National Academy Press.

King, F.J., Goodson, L., \& Rohani, F. (1998). Higher order thinking skills: Definitions, strategies, assessment. Tallahassee, FL: Center for Advancement of Learning and Assessment.

Kosslyn, S.M. (2017). Introducing psychology, brain, person, group. Moorpark, CA: Content Technologies.

Leikin, R. (2009). Exploring mathematical creativity using multiple solution tasks. In R. Leikin, A. Berman, \& B. Koichu (Eds.), Creativity in mathematics and the education of gifted students (pp. 129-145). Rotterdam: Sense Publishers.

Leikin, R. (2013). Mathematical creativity: The interplay between multiplicity and insight. Psychological Test and Assessment Modeling, 55(4), 385-400. Available
from http://www.psychologie-aktuell.com/fileadmin/download/ptam/4-2013 from http://www.psych

Leikin, R., \& Kloss, Y. (2011). Mathematical creativity of 8th and 10th grade students. In M. Pytlak, T. Rowland, \& E. Swoboda (Eds.), Proceedings of the 7 th Conference In M. Pytlak, T. Rowland, \& E. Swoboda (Eds.), Proceedings of the 7th Conference of the European Society for Research in Mathematics Education (pp. 1084-1093). Rzeszñw, Poland: European Society for Research in Mathematics Education.
Available from http://www.mathematik.uni-dortmund.de/ erme/doc/cerme7/ Available from

Levav-Waynberg, A., \& Leikin, R. (2012). The role of multiple solution tasks in developing knowledge and creativity in geometry. Journal of Mathematical Behavior, 31(1), 73-90. https://doi.org/10.1016/j.jmathb.2011.11.001

Mann, E.L. (2005). Mathematical creativity and school mathematics: Indicators of mathematical creativity in middle school students. Unpublished doctoral dissertation. University of Connecticut, Storrs, Connecticut, United States. Available from http://digitalcommons.uconn.edu/dissertations/AAl3205573/

Mann, E.L. (2006). Creativity: The essence of mathematics. Journal for the Education of the Gifted, 30(2), 236-260. https://doi.org/10.4219/jeg-2006-264
Marin, L.M., \& Halpern, D.F. (2011). Pedagogy for developing critical thinking in adolescents: Explicit instruction produces greatest gains. Thinking Skills and Creativity, 6(1), 1-13. https://doi.org/10.1016/j.tsc.2010.08.002

Melhem, T., \& Isa, Z. (2013). Enhancing critical thinking skills among students with learning difficulties. International Journal of Academic Research in Progressive Education and Development, 2(4), 151-169. https://doi.org/10.6007/JJARPED/v2-i4/395

Mihajlović, A., \& Dejić, M. (2015). Using open-ended problems and problem posing activities in elementary mathematics classroom. In F.M. Singer, F. Toader, \& C. Voica (Eds.), Proceedings of the Ninth Mathematical Creativity and Giftedness International Conference (pp. 34-39). Sinaia, Romania: The International Group for Mathematical Creativity and Giftedness. Available from http://www.mcg-9. net/pdfuri/MCG-9-Conference-proceedings.pdf

Misra, I. (2003). Openness to experience: Gender differences and its correlates. Journal of Personality and Clinical Studies, 19, 141-151.

Montgomery, D.C. (2013). Design and analysis of experiments. (8th edn.). New York, NY: Wiley.

National Council of Teachers of Mathematics. (2000). Principles and standards for school mathematics. Reston, VA: NCTM.

Nori, Z. (2002). Gender differences creativity, academic achievement (mathematics, sciences and language of literature) among high school in city of Shiraz. Unpublished doctoral dissertation. University of Shiraz, Shiraz, Iran.

Papastephanou, M., \& Angeli, C. (2007). Critical thinking beyond skill. Educational Philosophy and Theory, 39(6), 604-621. https://doi.org/10.1111/j.1469-5812. 2007.00311.x

Park, J., \& Kwon, O. (2006). Cultivating divergent thinking in mathematics through an open-ended approach. Asia Pacific Educational Review, 7(1), 51-61. https://doi. org/10.1007/BF03036784

Piggott, J. (2011). Cultivating creativity. Available from https://nrich.maths.org/5784

Shapiro, S.S., \& Wilk, M.B. (1965). An analysis of variance test for normality (complete samples). Biometrika, 52, 591-611. https://doi.org/10.1093/biomet/52.3-4.591

Sriraman, B. (2005). Are giftedness and creativity synonyms in mathematics? An analysis of constructs within the professional and school realms. The Journal of Secondary Gifted Education, 17, 20-36.

Stepanek, J. (1999). Meeting the needs of gifted students: Differentiating mathematics and science instruction. Portland, OR: Northwest Regional Educational Laboratory. Available from http://educationnorthwest.org/sites/default/files/12.99.pdf

Torrance, E.P. (1962). Guiding creative talent. Englewood Cliffs, NJ: Prentice Hall. https://doi.org/10.1037/13134-000

Torrance, E.P. (1966). The Torrance tests of creative thinking-norms-technical manual research edition-verbal tests, Forms $A$ and $B$ - Figural tests, Forms $A$ and $B$. Princeton, NJ: Personnel Press.

Torrance, E.P. (1972). Can we teach children to think creatively? The Journal of Creative Behavior, 6, 114-143. https://doi.org/10.1002/j.2162-6057.1972.tb00923.x

Williams, K.C., \& Williams, C.C. (2011). Five key ingredients for improving student motivation. Higher Education Journal, 12(1), 1-23. Available from http://www. aabri.com/manuscripts/11834.pdf

Wilson, A. (2005). Creativity in primary education: Theory and practice (achieving QTS cross-curricular strand). Exeter: Learning Matters Ltd.

Yazgan-Sağ, G., \& Emre-Akdoğan, E. (2016). Creativity from two perspectives: Prospective mathematics teachers and mathematician. Australian Journal of Teacher Education, 41(12), 25-40. https://doi.org/10.14221/ajte.2016v41n12.3 


\section{Appendix 1 \\ Example of a lesson}

Work in groups to answer the following questions and reflect.

Question 1: Which of the following numbers is the exceptional one: $21,25,26,33$ ?

Reflection 1: Reflect on the exceptional number question.

Question 2: Write the following term in the sequence: 2, 3,

Reflection 2: Reflect on the following term question.

Question 3: What is the drawing and what is the background?

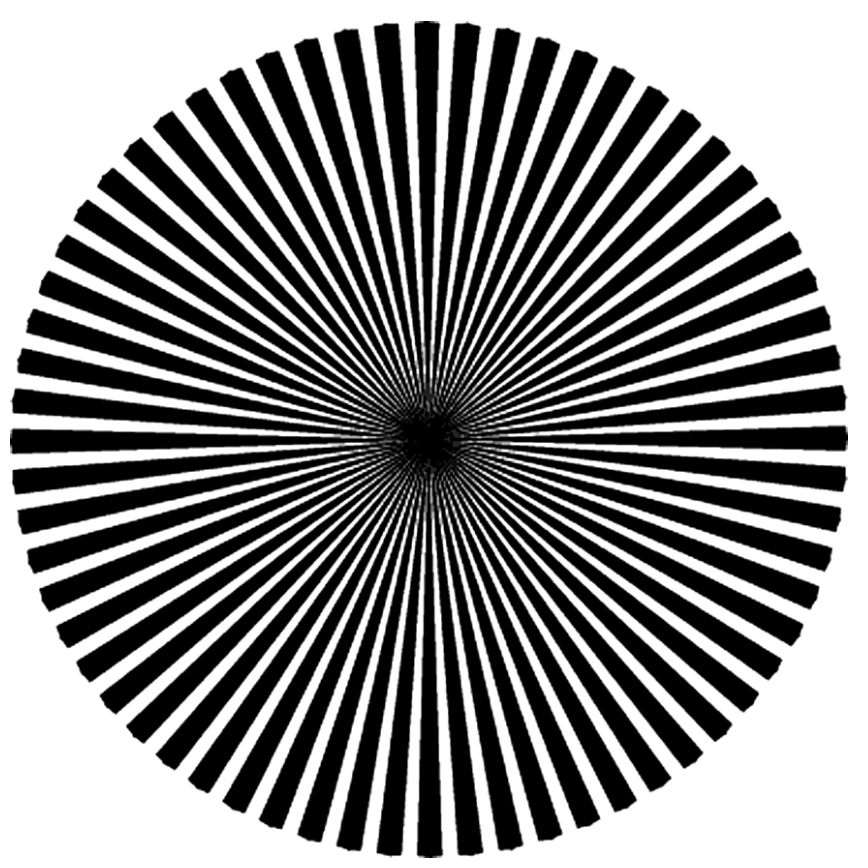

Reflection 3: Reflect on the drawing and background question.

Question 4: Search for a classic painting on the internet. Discuss what the painting is about without searching for information on the painting.

Reflection 4: Reflect on the painting question.

Reflection 5: Reflect on the previous four questions. 


\section{Appendix 2 \\ Multiple solutions to a problem}

Some solutions for the problem 'Which of the following numbers is the exceptional one: 21, 25, 26, 33?':

21 is exceptional for it has 7 as a factor,

21 is exceptional for it has 21 as a factor,

25 is exceptional for it has 5 as a factor,

25 is exceptional for it has 25 as a factor,

26 is exceptional for it has 2 as a factor,

26 is exceptional for it has 13 as a factor,

26 is exceptional for it has 26 as a factor,

33 is exceptional for it has 11 as a factor,

33 is exceptional for it has 33 as a factor,

25 is exceptional for it is a square number,

26 is exceptional for it is an even number,

33 is exceptional for it is greater than 30 . 


\section{Appendix 3}

Example of students' discussion and reflection on the questions in the CoRT creativity unit

Wasim: At the beginning I thought only number 33 is exceptional because both of its digits are similar.

Ruba: I also thought that 25 is the only exceptional number because it is a square number.

Salma: This is the first time I have a question like this. It's a beautiful question. I find this question interesting.

Wasim: Yes, we never had a question like this in the class. They give more freedom for the students to answer questions.

Salma: I found difficulty in solving the question. I think we should be involved with more questions like this. They open our minds.

Ruba: I am sure I will be more open-minded in other questions and try to be more creative in answering mathematical questions. 